\title{
Proposing Design Principles for Sustainable Fire Safety Training in Immersive Virtual Reality
}

\author{
Amir Haj-Bolouri \\ University West, Sweden \\ amir.haj-bolouri@hv.se
}

\author{
Matti Rossi \\ Aalto University, Finland \\ matti.rossi@aalto.fi
}

\begin{abstract}
Immersive Virtual Reality (IVR) technologies are frequently adopted by organizations for safety training. Safety training in IVR engages and motivates employees to develop skills in how to manage hazardous situations. By employing IVR for safety training, organizations and employees can develop safety knowledge and increase their sustainability awareness. In this paper we develop design principles for sustainable fire safety training in IVR. The principles were developed through an Action Design Research (ADR) case. The paper demonstrates how $A D R$ can be used to design individual training environments and how the method supports the development of more generic design principles for such environments. The design principles are subsequently proposed as: Design for Multimodal Risk Perception, Design for Empathetic Safety Cognition, Design for Formative Hazard Inspection, and Design for Comfort in Uncomfortable Decision Making.
\end{abstract}

\section{Introduction}

The recent progress and re-emergence of immersive technologies as commercially viable technology has resulted in the introduction of high-end consumer-grade Immersive VR (IVR) hardware products such as the Oculus Rift and HTC Vive [1]. As a consequence, organizations in the industrial sector (e.g., manufacturing, mining, construction, transportation) have become increasingly keen to adopt and employ IVR for facilitating training and learning activities that enhance their employees' competency and skills [2-4]. For instance, IVR-based learning environments make it possible for employees to visit places and do things that are not otherwise possible or too dangerous for them [5]. In addition, IVR allows employees' cognition to shift from representational learning (e.g., descriptions) to conceptual learning (e.g., concepts) [6], to meaningful learning that has a direct relevancy and effect for the employee's professional skills and competency [7]. One area in particular that stresses the meaningfulness of IVR environments for competency development, is the area of safety training with a particular focus on fire safety.

Traditional fire safety training can be dangerous for employees and a high cost for organizations [8]. The advantage of IVR is to simulate the fire scene, so that the trainees can immerse themselves into virtual environments [9]. The trainees can for example actively interact with the learning environments through exploring the virtual space, which makes it easier for the trainees to develop necessary competency without being hurt [10-11]. Moreover, the 'reality' of IVR allows for immersion, increased presence, interaction, and imagination, which in turn facilitate trainees' active development of knowledge [12]. Consequently, the knowledge development supports the obtaining of meaningful skills that can be applied to additional fire safety training settings, and its transformation to solving practical problems [13].

\section{1. Research Problem, Aim, and Question}

Despite the increasing interest and usage of IVR for fire safety training among organizations in the industrial sector, research within Information Systems (IS) have paid relatively minimal attention to study IVR for safety training [14]. Historically, researchers within the IS field, such as Walsh \& Pawlowski [15, p. 297], once pointed out that IVR is "[...] a technology in need of IS research", whereas most seminal IS studies [e.g., 16-18] have focused on virtual worlds or environments rather than IVR technology. Moreover, recent IS studies [6] [19-21] emphasize IVR technology from a broader perspective of education and learning, rather than safety training in particular. In other interrelated fields however, such as human-computer interaction (HCI), engineering, and educational sciences, several studies [10-13] [22-24] stress the importance of advancing the scientific discourse on VR and safety training, especially with an emphasis on producing prescriptive knowledge such as design principles.

The development of design principles has been a prevalent endeavor of Design Science Research (DSR) in IS [25-26]. Studies [27-29] report the viability of developing design principles for capturing and 
informing the design process of Information Technologies (IT), for both practitioners and scholars. For practitioners, design principles are beneficial because they provide development reliability and plausibility of success by providing guidelines derived from both theory and the design process, which demarcate the range of system features and development activities to a more manageable set [25]. For scholars, design principles provide captured knowledge that are open to empirical testing and thus can form a basis for a design theory [26]. To this day however, research that informs the development of design principles for safety training in IVR is minimal in general, and essentially non-existing in the IS literature in particular.

As a response to the identified gap, and the need to produce prescriptive knowledge for IVR and safety training, this paper develops and proposes a set of design principles that advances the research on IVR and safety training in IS. The purpose of the design principles is to offer theory-based guidance for the design of IVR applications that support fire safety training in a sustainable way. With 'sustainability' we refer to the socio-economic and environmental dimensions of safety training, which are improved when shifting from conducting safety training in physical environments to IVR environments [30-31]. Developing and proposing design principles that incorporate sustainability dimensions for safety training is thus important, because it helps organizations to improve sustainability goals that resonate with the global 2030 agenda of United Nations [32]. Hence, in order to guide this study and fulfill the research aim, we propose the following research question:

\section{- How can immersive Virtual Reality applications be designed to support fire safety training in a sustainable way?}

The research question is addressed through an Action Design Research (ADR) [33] case in the rail industry sector with a focus on IVR and fire safety training onboard trains. The result is a set of proposed design principles for sustainable fire safety training and their implications for future IS research. Subsequently, we position our work in the domain of safety training and IVR, as well as the stream of emerging publication trend on VR studies in the IS field, which is clearly showing positive interests for an advancement of IS research and VR; e.g., example, conferences such as Hawaii International Conference (HICSS) [34] and journals such as the Journal of Management Information Systems (JMIS) [35] have encouraged IS researchers to focus VR studies through dedicated conference tracks and special issues.

The rest of this paper is organized as follows. First, we identify related research on IVR, safety training and sustainability. Second, we present the ADR method and depict the empirical setting of the ADR case. Third, we guide the reader through the ADR cycles and their outcomes. Fourth, we present and propose the design principles. Finally, we present a concluding discussion about the design principles and provide a brief outlook for future research.

\section{Related Research}

\subsection{IVR Characteristics}

IVR is a set of technologies that give people an immersive experience of a virtual world beyond the physical reality. IVR technologies are characterized through three main characteristics: presence, interactivity, and immersion [36]. Presence is typically understood as the feeling of being physically somewhere other than where one actually is located [14], whereas interactivity influences the feeling of presence and refers to the extent which users can manipulate their virtual environment in real time [1]. Finally, immersion is attributed as the feeling of becoming completely absorbed and surrounded by an enclosing IVR space, which increases the level of interactivity and sensations of presence among users. Subsequently, the three mentioned characteristics should be taken into consideration when designing, organizing, and conducting safety training in IVR [4] [21].

\subsection{Safety Training in IVR}

Safety training in IVR is an expanding application area among organizations in the industrial sector because it resolves many of the problems of organizing and conducting safety training in traditional physical settings [22]. This includes managing dangerous training activities under secure circumstances with lowcost features to increase employees' safety performance [21], without diminishing a high degree of realism [37]. Examples of areas where IVR is frequently employed for safety training include: construction engineering [38], mine personnel [39], community-based pedestrians [40], and the rail industry [41].

Knowledge outcomes of safety training in an IVR environment enhances employees' safety knowledge, risk perception, safety motivation, and overall safety performance [37-38]. And in order to map safety training scenarios sufficiently with dangerous real-life 
situations, it is critical that the design of such scenarios incorporate the working environments and lived experiences of the participants [22]. Hence, design plays a crucial role, but at the same time, most seminal IS studies [17-18] [29] related to VR have primarily been studying the design of virtual worlds or virtual environments rather than IVR and safety training. In addition to IS [14], in other fields (e.g., HCI, engineering, educational sciences) where studies on IVR and safety training have prevalent, researchers [13] [8-10] have stressed an urging need for design researchers across disciplines to produce prescriptive knowledge for safety training in IVR. Especially related to safety training and sustainability.

\subsection{Towards Sustainable Safety Training in IVR}

Sustainability issues are one of our times' main concerns and include a complex set of interconnected environmental, social, and economic problems. The sustainable development goals (SDGs) set by the United Nations (UN) for 2030 involve the three dimensions (environmental, social, and economic), requiring, at the same time a massive reduction of resources' use and their accessibility to the whole global population [32]. This radical transformation determines a need to educate citizens, organizations, and professionals, increase their awareness, and ultimately support a behavior change towards sustainable choices. To this purpose, IVR has been identified as a promising technology, especially for safety training that improves organizations' sustainability development [9] [24] |30-31].

Organizing and conducting safety training in IVR environments helps organizations to increase their awareness on SDGs and issues [30-31]. Safety training in IVR reduces environmental issues as well as increases the quality of socio-economic outcomes for organizations, in terms of promoting low-cost initiatives that are efficient for developing meaningful knowledge and skills among employees [39-40]. And while many frameworks and models have been developed to support design for sustainable behavior and decision improvements among organizations in general [42-45], to this day, there is a lack of prescriptive knowledge in form of design principles that guide and support the design of IVR experiences for sustainable safety training [14] [46].

\section{Research Approach}

Our overarching research approach for developing design principles follows the advice of Sein et al [33] through Action Design Research (ADR). Sein et al's [33] ADR-approach was selected because it provides a sufficient method and framework for organizing and conducting design research that emphasizes: (i) processes for building, intervening and evaluating (BIE) IT-artifacts in organizational settings; and (ii) produce prescriptive knowledge that can be formalized and proposed as design principles. The ADRframework is shown in Figure 1.

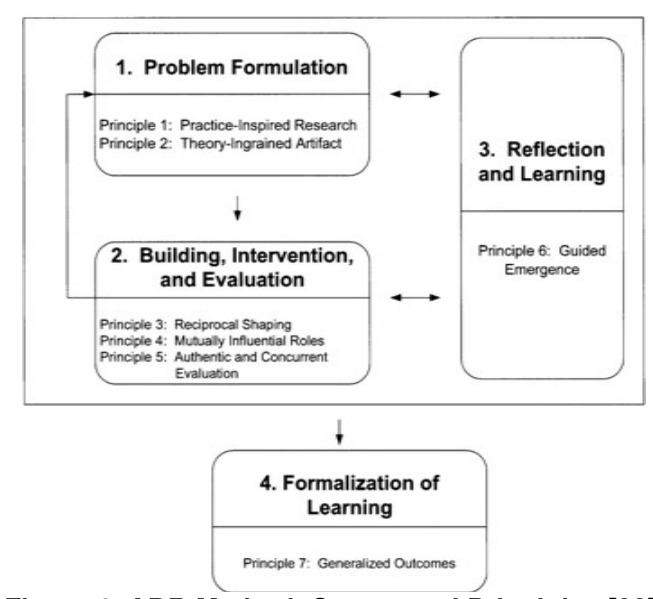

Figure 1. ADR Method: Stages and Principles [33]

The ADR-approach advocates development of design principles that are extracted through iterative cycles of BIE (Stage 2 in Figure 1) together with stakeholders in organizational settings. Subsequently, principles of the four ADR-stages (as shown in Figure 1) guide active participation and collaboration among members of an ADR team (e.g., researchers, stakeholders), as well as stimulating a reflective research practice that balances viable outcomes (e.g., IT-applications) with generalizable design principles. With 'generalizable' we mean that the maturity and abstraction level of principles has the potential to grow over time and cycles, addressing a class of problems, rather than being static. This is similar to nascent prescriptive knowledge in DSR [47-48], which are proposed at a certain stage of a research project and then revisited and refined through additional empirical activities and support of kernel theories [26] [28].

\subsection{The ADR Cycle}

Although the research project is still ongoing, this study reports outcomes from one ADR cycle which was performed between the beginning of 2020 and beginning of 2021. The cycle was implemented through The Generic Schema for Organization-Dominant BIE, in order to focus on the stages of evaluation, reflection and learning, and formalization of learning outcomes. Sein et al [18, p. 43] suggest the schema as suited for 
projects that aim to develop design principles through BIE-activities early on in the project. The cycle and its subsequent outcomes are illustrated in Figure 2.

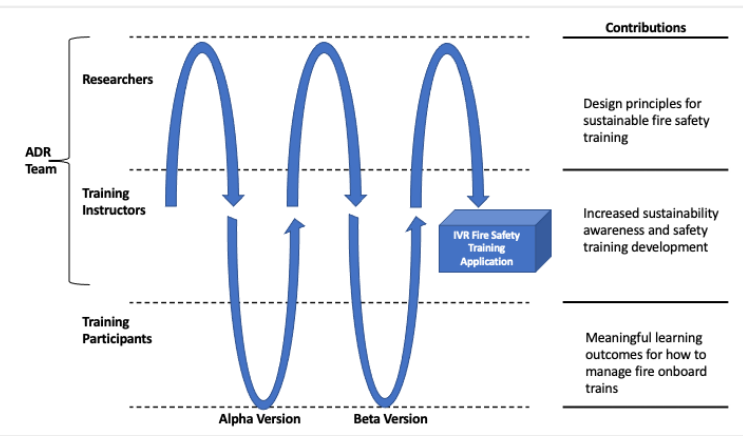

Figure 2. ADR Cycle: Generic Schema for OrganizationDominant BIE adapted from [33]

The ADR cycle was executed at one of the headquarters for the biggest rail industry organization in Sweden, named SJ. The cycle was manifested through a specific focus on evaluation of a designed IVR application for fire safety training. The IVR application had undergone two iterations of design for Alpha and Beta versions, which were now available for evaluation. More specifically, the evaluation focused on two aspects: (i) to evaluate the meaningful learning experience of participants in terms of increased skills and competency; (ii) to identify design implications for further improvement of the IVR application. Consequently, the evaluation phase was conducted through direct observations of safety training sessions and group interviews together with participants of the training sessions.

\subsection{Research Participants and Interviews}

A total of 26 participants were interviewed, divided in 4 different groups and training sessions. The participants of the group consisted of instructors and participants of the safety training program (shown in Table 1). The participants were different people for each group, whereas two instructors were proliferated among two groups each, meaning that there was a total of 2 instructors involved throughout the safety training sessions.

Table 1. Summary of Group Interviews

\begin{tabular}{|l|l|l|l|}
\hline Group & Participants & IVR Experience & Duration \\
\hline Group 1 & -2 train & - None of the & 36 \\
& drivers & $\begin{array}{l}\text { participants had any } \\
\text { prior experience }\end{array}$ & minutes \\
\hline
\end{tabular}

\begin{tabular}{|c|c|c|c|}
\hline & $\begin{array}{l}-3 \text { train } \\
\text { conductors } \\
-1 \text { instructor }\end{array}$ & $\begin{array}{l}\text { with IVR } \\
\text { technologies } \\
\text { - The instructor had } \\
\text { beginners level } \\
\text { experience }\end{array}$ & \\
\hline Group 2 & $\begin{array}{l}-6 \text { train } \\
\text { drivers } \\
-1 \text { instructor }\end{array}$ & $\begin{array}{l}\text { - } 1 \text { participant had } \\
\text { prior experience } \\
\text { with IVR in the } \\
\text { context of gaming } \\
\text { - The instructor had } \\
\text { beginners level } \\
\text { experience }\end{array}$ & $\begin{array}{l}50 \\
\text { minutes }\end{array}$ \\
\hline Group 3 & $\begin{array}{l}-3 \text { train } \\
\text { drivers } \\
-2 \text { managers } \\
-3 \text { train } \\
\text { conductors } \\
-1 \text { instructor }\end{array}$ & $\begin{array}{l}\text { - } 1 \text { participant had } \\
\text { prior experience } \\
\text { with IVR and } \\
\text { training for how to } \\
\text { drive the train } \\
\text { - The instructor had } \\
\text { beginners level } \\
\text { experience }\end{array}$ & $\begin{array}{l}56 \\
\text { minutes }\end{array}$ \\
\hline Group 4 & $\begin{array}{l}-3 \text { train } \\
\text { drivers } \\
-2 \text { train } \\
\text { conductors } \\
-1 \text { instructor }\end{array}$ & $\begin{array}{l}\text { - } 1 \text { participant had } \\
\text { prior experience } \\
\text { with IVR in the } \\
\text { context of gaming } \\
\text { - The instructor had } \\
\text { beginners level } \\
\text { experience }\end{array}$ & $\begin{array}{l}46 \\
\text { minutes }\end{array}$ \\
\hline
\end{tabular}

The training sessions and interviews were organized and executed according to the following steps.

In the first step, each group had an instructor that informed the groups about the process of safety training, showed the groups how to equip the VR headset and fire extinguisher (shown in Figure 3), and provided the groups a demonstration of the training scenario in VR.

As a second step, each participant of a group performed their safety training scenario. Each performance lasted between 3-8 minutes (Figure 4 shows one of the training participants).

As a third step, the participants participated in a semi-structured group interview. The protocol for interviews drew inspiration from guidelines proposed by scholars that advocate how to use qualitative research methods [49-50].

As a fourth step, each interview started with background questions such as: "Have you ever used VR before?", "What is your prior experience of VR and training?", "What is your professional role/title?" 
In the fifth step, each interview continued with questions that aim to highlight and comprehend the participant's experience. The more structured questions included questions such as: "What is your general feelings and thoughts about the VR training?", "In what ways did you experience the training scenario as relevant or valuable for you?", "If so, please explain more".

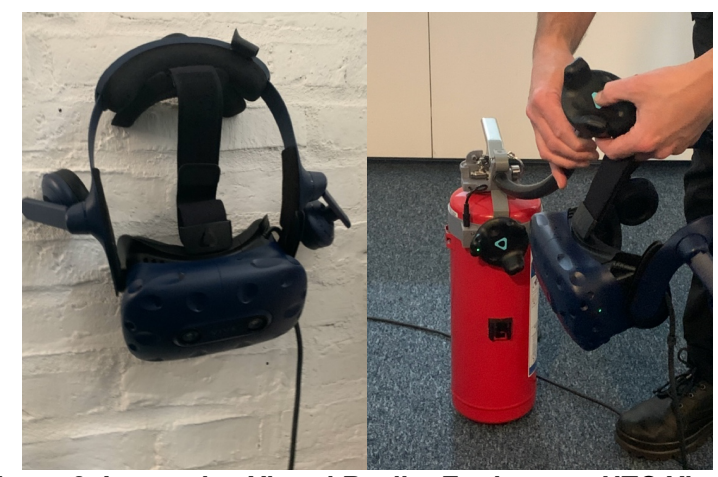

Figure 3. Immersive Virtual Reality Equipment: HTC Vive Pro Headset and Fire Extinguisher

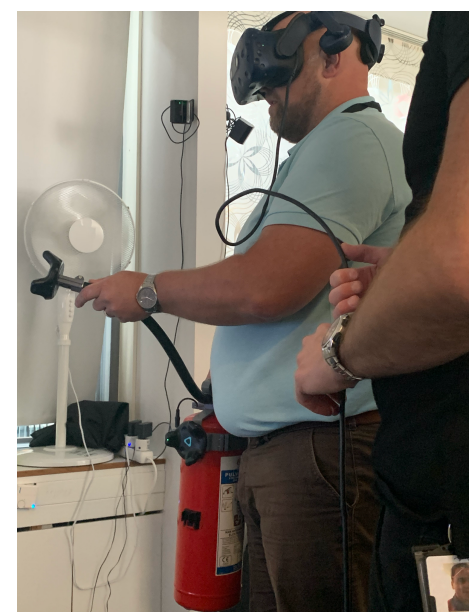

Figure 4. Participant Training Fire Safety with IVR Equipment

In addition to the structured questions, the interview continued more as a dialogue depending on the participants' responses in line with the semistructured approach, focusing the meaningfulness of their learning experience. Each interview was closed with evaluative questions such as: "Would you like to perform more training in VR?", "What challenges did you experience?". Consequently, we followed a qualitative approach for analysis of data into design principles, to benefit from the more inductive and exploratory character of qualitative research methods [51].

\section{Design Principles for Sustainable Fire Safety Training}

The qualitative analysis of group interviews and observations of the training sessions helped us extract and identify four design principles for sustainable fire safety training in IVR. In addition to case specific data and outcomes, the design principles do also incorporate design elements for safety training in IVR based on reviewed literature on sustainability and safety training in IVR. Unlike a design theory, the design principles are only explicit extractions on the way towards more developed knowledge base and design theory [26]. In addition, any proposed design principles may vary due to considered dimensions, design models, goals, involved designers, evaluation, and platforms [15]. Thus, we acknowledge that the proposed design principles of this study are delimited to the formalized ADR outcomes from the empirical case, and on-going for further development. Consequently, the design principles are targeted towards safety training in IVR in general whereas sustainable fire safety training is a special case of the safety training domain in IVR.

An overview of the design principles is depicted in Table 2 whereas a detailed description of each principle is described in the following sub-sections.

Table 2. Design Principles for Sustainable Fire Safety Training in Immersive Virtual Reality

\begin{tabular}{|l|l|}
\hline $\begin{array}{l}\text { Design } \\
\text { Principle }\end{array}$ & Description \\
\hline $\begin{array}{l}\text { DP1. Design } \\
\text { for Multimodal } \\
\text { Perception }\end{array}$ & $\begin{array}{l}\text { The design of sustainable fire safety training } \\
\text { environment in IVR needs to implement } \\
\text { design elements that provide interactive cues } \\
\text { and indicators about a situation's } \\
\text { safety/unsafety level }\end{array}$ \\
\hline $\begin{array}{l}\text { DP2. Design } \\
\text { for Empathetic } \\
\text { Safety } \\
\text { Cognition }\end{array}$ & $\begin{array}{l}\text { The design of sustainable fire safety training } \\
\text { environment in IVR needs to implement } \\
\text { design elements that ensure increased safety } \\
\text { awareness through behavioral skills training } \\
\text { and empathetic risk management }\end{array}$ \\
\hline $\begin{array}{l}\text { DP3. Design } \\
\text { for Formative } \\
\text { Hazard } \\
\text { Inspection }\end{array}$ & $\begin{array}{l}\text { The design of sustainable fire safety training } \\
\text { environment in IVR needs to implement } \\
\text { evaluative elements that make it possible to } \\
\text { inspect hazardous situations and formatively } \\
\text { reflect the quality of actions/consequences }\end{array}$ \\
\hline $\begin{array}{l}\text { DP4. Design } \\
\text { for Comfort in } \\
\text { Uncomfortable } \\
\text { Decision }\end{array}$ & $\begin{array}{l}\text { The design of sustainable fire safety training } \\
\text { environment in IVR needs to implement } \\
\text { design elements that encourages participants } \\
\text { to make mistakes through uncomfortable } \\
\text { sequences of trial-and-error, and learn from } \\
\text { their mistakes, in order to avoid them and } \\
\text { make wise decisions }\end{array}$ \\
\hline
\end{tabular}

\subsection{Design for Multimodal Risk Perception}

During a fire, passengers of a train are often vulnerable and await help from train personnel without 
deciding how to behave [9]. It is therefore very important for the train personnel to have increased skills in how to control and extinguish the fire as efficient as possible, without hurting themselves or any passengers. Perceiving risks, and possibilities of how to manage the risks sufficiently, needs thus to be multimodal and realistically conveyed in the IVR training environment [22]. More specifically, the IVR environment needs to stimulate risk perception through text, sound, visual objects, animation, haptic stimuli, and instructive avatars that are able to interact with and guide the participants throughout their training scenario [11]. Excerpts from the interviews with participants from the case specific fire training sessions express the viability of multimodal risk perception as follows.

"The behavior of the fire felt very realistic because it looked and sounded like a real fire." (Train Driver 1/Group 1)

"The fire increased and spread if I did not do anything about it, but I did not feel the heat" (Train Conductor 1/Group 2)

"It was easy to follow the audio-visual instructions for extinguishing the fire. I was able to both see and hear the instructions and the fire at the same time." (Train Driver 2/Group 1)

By incorporating design elements, such as interactive cues (e.g., danger signs) and indicators (e.g., level of danger), the IVR safety training environment informs participants about the level of safety/unsafety they are encountering [3]. For example, when the amount of fire increases onboard a train, the smoke spreads and signals in IVR that the situation is getting more and more critical (as shown in Figure 5). As a consequence, the user receives the critical information as how he/she would do in the physical reality, with the exclusion of sense of smell, and can judge the risk level sufficiently. Repeating such kind of training in IVR is thus not only socio-economically sustainable for the organization - due to reduced injuries and danger among the participants - but also increasingly sustainable for the environment due to the reduced amount of waste and smoke.

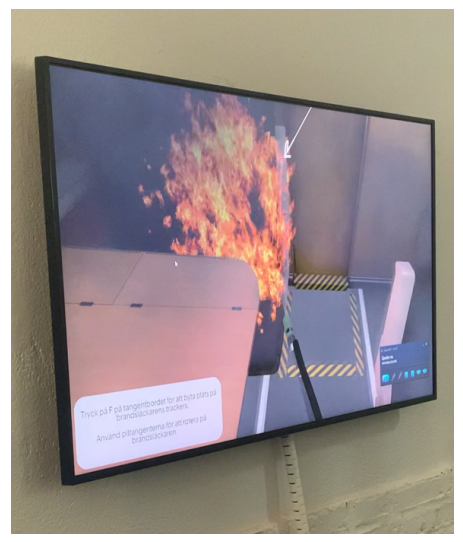

Figure 5. Increased Fire and Smoke in the IVR Training Environment

\subsection{Design for Empathetic Safety Cognition}

When a fire unleashes and increases onboard a train, the situation becomes stressful to manage for train personnel [9]. In IVR, the participants do not only learn how to manage the fire, but the participants also refine their behavioural skills in order to increase their empathetic safety cognition [3] [8]. Here, empathetic safety cognition refers to empathetic behaviour skills such as caring for the environment and surrounding and the people onboard the train (especially vulnerable ones, such as children, elderly, disabled people).

Moreover, the IVR environment allows the participants to iterate and refine their empathetic safety cognition skills without hurting anyone or destroying anything, as would be the risk in a physical training environment [4]. Hence, the design elements of the training environment need to incorporate training scenarios that stimulate behavioural skills training and increases the participants' empathetic safety cognition. Instructors of the safety training sessions stress this need accordingly.

"Increased safety is not only for us personnel onboard the train but first and foremost for our passengers. We must take care of them and look after their different needs during fire evacuation." (Instructor/Group 1)

"Our personnel have safety management skills, but it is first and foremost for extinguishing the fire. We need to train them how to manage the vulnerable situation with care, not only how to manage the fire. The situation is more complex than the danger of fire." (Instructor/Group 2)

By focusing on how to improve the personnel's empathetic safety cognition through IVR safety training, the design principle connects with the social sustainability dimension in two ways: (i) developing empathetic safety cognition in IVR is essentially to develop behavioural skills that ensures the safety of passengers and personnel [9], which supports increasing the social sustainability awareness of an organization [32]; (ii) increased social sustainability emphasizes the enhancement of personnel's confidence in how to manage safety situations in a mindful way [8] [43]; e.g., by preparing the personnel mentally and equipping them with social skills that enhances their empathy towards the situation [23] [46].

\subsection{Design for Formative Hazard Inspection}

When evaluating the safety performance of each personnel, data about the relationship between participants' professional roles and their prior experiences of safety management needs to be 
considered as well as how they have achieved the training objectives [13] [18]. In order to perform sufficiently, the participants need IVR features that allow them to formatively inspect the level of hazardousness for the safety of the environment (e.g., outburst of fire, outreach, spread of smoke) and passengers (e.g., distance between passengers and fire, vulnerability towards heat and smoke) [3] [9]. Figure 6 illustrates how hazardous inspection was manifested in the IVR training environment of this study - the green beam and circle indicates that it is safe to move to the spot without getting injured, whereas the pop-up text next to the fire indicates the level of fire and smoke.

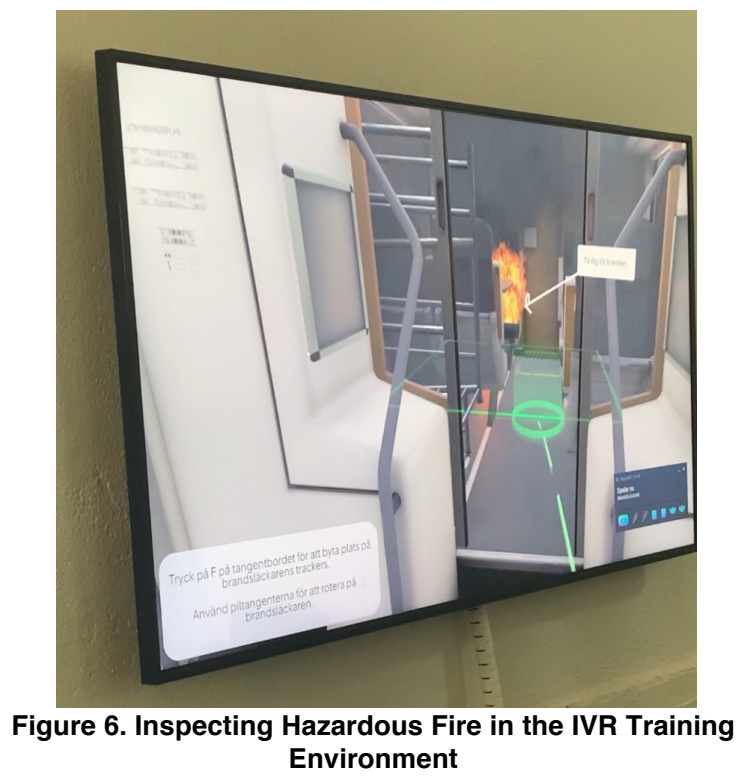

In the educational sciences, formative features of learning are considered as feasible for evaluating training performance and learning [6]. The formative approach is also desired to incorporate into IVR training/learning environments [19-20], so that instructors and participants can inspect and evaluate critical factors of the training process. Hence, allowing the users to inspect fire hazardousness, its implications for the chain of cause-and-effect around (e.g., fire, smoke, and how to handle it onboard a train), is a feature that the IVR environment needs to implement for instant evaluation (during the training session) and post evaluation (after the training session) [9] [41]. The managers of the organization expressed their views regarding this need accordingly.

\footnotetext{
"There is a need for our staff to develop their safety judgement under pressure and read the hazardous situation without injuring themselves. Virtual Reality seems good and realistic for doing so. We want them [the staff] to take their time and inspect the entire situation so they can cope with it later on in reality." (Manager 1/Group 3)
}

"We want our personnel to understand the cause and effect of fire onboard trains. They have education in how to work on trains, how the train functions, but during pressure, it is easy to forget. The safety training is important for them to investigate the dangerous circumstances and understand the solutions." (Manager 2/Group 3)

By implementing design features that allow to inspect the level of hazardousness, the organization can extract knowledge on environmental sustainability and judge how the pollution is reduced during IVR training. Furthermore, it is economically more sustainable for the organization to implement and use such features in an IVR environment, than it is to do it in a physical setting [46].

\subsection{Design for Comfort in Uncomfortable Decision Making}

During a stressful and unstable situation, the train personnel need to be mentally prepared for making uncomfortable decisions that affect the outcome of an entire situation [9]. The more stressful the situation becomes, the higher the possibility of making detrimental decisions, unless one is prepared and trained prior for the safety situation at hand [10-11]. Hence, the IVR environment needs to be designed with features that allow the participant to repeat his/her mistakes without any injuries, in order to develop skills that are turned into sufficient routine behaviour [4]. Finding comfort in an uncomfortable situation is thus a question of being prepared mentally and logistically; mentally in terms of having a calm attitude (e.g., keeping a steady pace of breathing) and logistically in terms of having access to supportive means (e.g., fire extinguisher, access to wagons, evacuation doors).

The IVR training environment needs to drill and prepare the personnel realistically through simulated scenarios that allow them to make faulty decisions, and grasp their implications for the situation, in a meaningful way [7]. The level of increased presence and immersion in IVR [13] [36] makes it possible to simulate already known safety scenarios that require uncomfortable decision makings, as well as to simulate imaginary scenarios for potential danger and safety management [31]. Experiences of such dual simulation feature was expressed by participants as follows.

"I have different responsibilities than a train driver. I need to manage passengers all day long and I have first-hand experience of everything. During a fire I need to make decisions fast and efficient and not freeze due to fear." (Train Conductor 1/Group 4)

"Driving the train is easy but doing so during a fire or something extreme, is difficult. I need to take decisions on how to stop the train, how to evacuate, and what to communicate to passengers without scaring them. This is challenging but I get a routine through training." (Train Driver 1/Group 4) 
By preparing the personnel for being steady, focused, and finding comfort under uncomfortable circumstances, they can calm down the situation and make proper decisions. Training for such a preparation in an IVR training environment, is not only socially sustainable for the organization but also economically sustainable; it is socially sustainable because the personnel develop social skills that equip them for reducing risks during a fire [8-9], and economically sustainable because the negative implications of making detrimental decisions do not directly influence the physical reality [46].

\section{Conclusion}

In this paper we asked how to design IVR applications that support fire safety training in a sustainable way. We addressed they question by developing and proposing four design principles for sustainable fire safety training: Design for Multimodal Risk Perception, Design for Empathetic Safety Cognition, Design for Formative Hazard Inspection, and Design for Comfort in Uncomfortable Decision Making. The utility of the principles is proposed to: inform designers how to incorporate sustainability dimensions into the design of IVR safety training environment; provide means for training personnel in taking the right actions and preparing for hazardous situations in a controlled and safe environment. The principles were identified and developed through an ADR project, which evaluated an immersive virtual training environment prototype. The ADR project, where we tested this in practice resonated with literature on VR and safety training in general, in the sense that:

- IVR allows for safe and sustainable repeated training in hazardous environments [9-11]

- IVR engages the participants and instructors to solve safety problems together [24]

- IVR allows organizations to simulate both already known safety scenarios as well as imaginary safety scenarios [21]

- IVR training environments go beyond traditional training mediums [22] and absorbs participants into immersive experience with increased sense of presence (both among participants, instructors, as well as virtual avatars and objects) [13]

This study demonstrates on one hand that the ADR method can be used to develop advanced immersive virtual training environments for real world safety training purposes, and on the other hand that IVR can be used to develop realistic environments for safety training. Furthermore, the use of commercial of the shelf VR equipment makes this kind of training environment sustainable both environmentally and socioeconomically. The limitations of this study are demarcated to only one ADR cycle and empirical case. Hence, for future work, we propose to test and evaluate the design principles for similar IVR safety training contexts. Doing so, research can gradually advance the design principles towards a higher level of generalizability, in terms of how to design sustainable safety training environments in IVR.

\section{References}

[1] Anthes, C., Garcia-Hernandez, R.J., Wiedemann, M., Kranzlmuller, D. (2016). State of the art virtual reality technology. In IEE Aerospace Conference, 1-9.

[2] Carruth, D. W. (2017). Virtual reality for education and workforce training. In $15^{\text {th }}$ International Conference on Emerging eLearning Technologies and Applications (ICETA), 1-6.

[3] Feng, Z, González, V. A., Amor, R., Lovreglio, R., \& Cabrera-Guerrero, G. (2018). Immersive virtual reality serious games for evacuation training and research: A systematic literature review. Computers \& Education, 127, 252-266.

[4] Jensen, L., \& Konradsen, F. (2018). A review of the use of virtual reality head-mounted displays in education and training. Education and Information Technologies, 23(4), 1515-1529.

[5] Freina, L., \& Ott, M. (2015). A literature review on immersive virtual reality in education: State of the art and perspectives. Paper presented at the The International Scientific Conference eLearning and Software for Education, 1133.

[6] Fromm, J., Radianti, J., Wehking, C., Stieglitz, S., Majchrzak, T. A., \& vom Brocke, J. (2021). More than experience?-On the unique opportunities of virtual reality to afford a holistic experiential learning cycle. The Internet and Higher Education, 50, 100804.

[7] Vergara, D., Extremera, J., Rubio, M. P., \& Dávila, L. P. (2019). Meaningful learning through virtual reality learning environments: A case study in materials engineering. Applied Sciences, 9(21), 4625.

[8] Howard, M. C., \& Gutworth, M. B. (2020). A metaanalysis of virtual reality training programs for social skill development. Computers \& Education, 144, 103707.

[9] Fu, Y., \& Li, Q. (2020). Immersive Virtual Reality for Fire Safety Behavioural Skills Training via Gesture-based 
Technology. In IOP Conference Series: Materials Science and Engineering (Vol. 825, No. 1, p. 012015). IOP Publishing.

[10] Shaoyang, Q., \& Hongxiang, R. (2018). Ship life-saving training system based on virtual reality technology. In 2018 IEEE 4th International Conference on Control Science and Systems Engineering (ICCSSE) (pp. 559-563). IEEE.

[11] Zhu, H., Qin, X., Yang, C., \& Nan, C. (2014). The development of mine fire rescue VR training system based on Virtools. Mining research and development, 34(04), 9598 .

[12] Coelho, C., Tichon, J. G., Hine, T. J., Wallis, G. M., \& Riva, G. (2006). Media presence and inner presence: the sense of presence in virtual reality technologies. In From communication to presence: Cognition, emotions and culture towards the ultimate communicative experience (pp. 25-45). IOS Press, Amsterdam.

[13] Buttussi, F., \& Chittaro, L. (2017). Effects of different types of virtual reality display on presence and learning in a safety training scenario. IEEE transactions on visualization and computer graphics, 24(2), 1063-1076.

[14] Wohlgenannt, I., Simons, A., \& Stieglitz, S. (2020). Virtual reality. Business \& Information Systems Engineering, 62(5), 455-461.

[15] Chaturvedi AR, Dolk DR, Drnevich PL (2011) Design principles for virtual worlds. Manag Inf Syst Q 35(3):673684.

[16] Walsh KR, Pawlowski SD (2002) Virtual reality: a technology in need of IS research. Commun Assoc Inf Syst 8(20):297-313

[17] Davis A, Murphy J, Owens D, Khazanchi D, and Zigurs, I. (2009). Avatars, people, and virtual worlds: foundations for research in metaverses. J Assoc Inf Syst 10(2):90-117.

[18] Pannicke D, Zarnekow R (2009) Virtual Worlds. Bus Inf Syst Eng 2:185-188.

[19] Radianti, J., Majchrzak, T. A., Fromm, J., \& Wohlgenannt, I. (2020). A systematic review of immersive virtual reality applications for higher education: Design elements, lessons learned, and research agenda. Computers \& Education, 147, 103778.

[20] Radianti, J., Majchrzak, T. A., Fromm, J., Stieglitz, S., \& Vom Brocke, J. (2021). Virtual Reality Applications for Higher Educations: A Market Analysis. In Proceedings of the 54th Hawaii International Conference on System Sciences ( $\mathrm{p}$. 124).

[21] Wang, Y. T., Lin, K. Y., \& Huang, T. (2021). An analysis of learners' intentions toward virtual reality online learning systems: a case study in Taiwan. In Proceedings of the 54th Hawaii International Conference on System Sciences (p. 1519).

[22] Leder, J., Horlitz, T., Puschmann, P., Wittstock, V., \& Schütz, A. (2019). Comparing immersive virtual reality and powerpoint as methods for delivering safety training: Impacts on risk perception, learning, and decision making. Safety science, 111, 271-286.

[23] Checa, D., \& Bustillo, A. (2020). A review of immersive virtual reality serious games to enhance learning and training. Multimedia Tools and Applications, 79(9), 55015527.

[24] Çakiroğlu, Ü., \& Gökoğlu, S. (2019). Development of fire safety behavioral skills via virtual reality. Computers \& Education, 133, 56-68.

[25] Hevner, A. R., March, S. T., Park, J., \& Ram, S. (2004). Design science in information systems research. MIS quarterly, 75-105.

[26] Gregor, S., \& Hevner, A. R. (2013). Positioning and presenting design science research for maximum impact. MIS quarterly, 337-355.

[27] Seidel, S., Chandra Kruse, L., Székely, N., Gau, M., \& Stieger, D. (2018). Design principles for sensemaking support systems in environmental sustainability transformations. European Journal of Information Systems, 27(2), 221-247.

[28] Gregor, S., Chandra Kruse, L., \& Seidel, S. (2020). Research Perspectives: The Anatomy of a Design Principle. Journal of the Association for Information Systems, 21(6), 2.

[29] Chaturvedi, A. R., Dolk, D. R., \& Drnevich, P. L. (2011). Design principles for virtual worlds. Mis Quarterly, 673-684.

[30] Salah, B., Abidi, M. H., Mian, S. H., Krid, M., Alkhalefah, H., \& Abdo, A. (2019). Virtual reality-based engineering education to enhance manufacturing sustainability in industry 4.0. Sustainability, 11(5), 1477.

[31] Joshi, S., Hamilton, M., Warren, R., Faucett, D., Tian, W., Wang, Y., \& Ma, J. (2021). Implementing Virtual Reality technology for safety training in the precast/prestressed concrete industry. Applied ergonomics, 90, 103286.

[32] United Nations Environment Programme (UNEP). (2013). "Frequently Asked Questions on Corporate Sustainability Reporting. Tackling the Big Questions Around the Global Corporate Sustainability Reporting Agenda." https://wedocs.unep.org/bitstream/handle/20.

500.11822/26171/FAQ_Corporate_Sustainability.pdf?seque nce $=1 \&$ is Allowed $=y$.

[33] Sein, M. K., Henfridsson, O., Purao, S., Rossi, M., \& Lindgren, R. (2011). Action design research. MIS quarterly, $37-56$. 
[34] Parvinen P, Hamari J, Pöyry E (2018) Introduction to minitrack: mixed, augmented and virtual reality.

In: Proceedings of the 51st Hawaii international conference on system sciences, Big Island

[35] Cavusoglu H, Dennis AR, Parsons J (2019) Special issue: immersive systems. J Manag Inf Syst 36(3):680-682

[36] Mütterlein, J. (2018). The three pillars of virtual reality? Investigating the roles of immersion, presence, and interactivity. In Proceedings of the 51st Hawaii international conference on system sciences.

[37] Pena, A. M., \& Ragan, E. D. (2017). Contextualizing construction accident reports in virtual environments for safety education. In 2017 IEEE Virtual Reality (VR) (pp. 389-390). IEEE.

[38] Sacks, R., Perlman, A., \& Barak, R. (2013). Construction safety training using immersive virtual reality. Construction Management and Economics, 31(9), 10051017.

[39] Zhang, H., He, X., \& Mitri, H. (2019). Fuzzy comprehensive evaluation of virtual reality mine safety training system. Safety Science, 120, 341-351.

[40] Schwebel, D. C., Combs, T., Rodriguez, D., Severson, J., \& Sisiopiku, V. (2016). Community-based pedestrian safety training in virtual reality: A pragmatic trial. Accident Analysis \& Prevention, 86, 9-15.

[41] Randeniya, N., Ranjha, S., Kulkarni, A., \& Lu, G. (2019). Virtual reality-based maintenance training effectiveness measures-a novel approach for rail industry. In 2019 IEEE 28th International Symposium on Industrial Electronics (ISIE) (pp. 1605-1610). IEEE.

[42] Withanage, C., Hölttä-Otto, K., Otto, K., \& Wood, K. (2016). Design for sustainable use of appliances: A framework based on user behavior observations. Journal of Mechanical Design, 138(10).

[43] De Medeiros, J. F., Da Rocha, C. G., \& Ribeiro, J. L. D. (2018). Design for sustainable behavior (DfSB): Analysis of existing frameworks of behavior change strategies, experts' assessment and proposal for a decision support diagram. Journal of Cleaner Production, 188, 402-415.

[44] Blizzard, J. L., \& Klotz, L. E. (2012). A framework for sustainable whole systems design. Design Studies, 33(5), 456-479.

[45] Tang, T., \& Bhamra, T. (2008). Changing energy consumption behaviour through sustainable product design. In DS 48: Proceedings DESIGN 2008, the 10th International Design Conference, Dubrovnik, Croatia.

[46] Scurati, G. W., Bertoni, M., Graziosi, S., \& Ferrise, F. (2021). Exploring the Use of Virtual Reality to Support
Environmentally Sustainable Behavior: A Framework to Design Experiences. Sustainability, 13(2), 943.

[47] Heinrich, P., \& Schwabe, G. (2014, May). Communicating nascent design theories on innovative information systems through multi-grounded design principles. In International Conference on Design Science Research in Information Systems(pp. 148-163). Springer, Cham.

[48] Göbel, H., \& Cronholm, S. (2016). Nascent design principles enabling digital service platforms. In International Conference on Design Science Research in Information System and Technology (pp. 52-67). Springer, Cham.

[49] Kallio, H., Pietilä, A. M., Johnson, M., \& Kangasniemi, M. (2016). Systematic methodological review: developing a framework for a qualitative semi-structured interview guide. Journal of advanced nursing, 72(12), 2954-2965.

[50] Berg, B.L., Qualitative Research Methods for the Social Sciences, Bacon \& Allyn, Boston, 1995. 